\title{
Sustainable Polymers Derived From Naturally Occurring Materials
}

\author{
Bimlesh Lochab, I. K. Varma, J. Bijwe \\ ${ }^{1}$ Department of Chemistry, Shiv Nadar University, Greater Noida, India \\ ${ }^{2}$ CPSE; ITMMEC, IIT, Delhi, New Delhi, India \\ Email: bimlesh_lochab@yahoo.com
}

Received 2012

\begin{abstract}
Nearly $95 \%$ of monomers or chemical intermediates used today are based on fossilized carbon such as coal and petroleum. This has resulted in a high rate of depletion of fossilized reserves, continuous escalation in petroleum prices, environmental impact with the increase in emission of greenhouse gases, and accumulation of non-biodegradable waste on earth. Current global main challenges are moving towards green sources - need for vast new and sustainable material resources; supplement, reuse and replace petroleum based polymeric materials; biodegradability of materials to prevent build up of waste; toxicity associated with the preparation, usage and environmental safety. Recent investigations are therefore, focused on procuring materials from the plant resources, agricultural waste and their utility in synthesis of polymeric materials. Amongst the polymers derived from natural resources poly(lactic acid) is a leading candidate. Commercial quantities of natural oil-based polyols such as castor, soya bean oil have been available over the past several years and currently used for synthesis of polyesters, polyurethanes etc, but today many other natural materials are also being investigated. It should be possible to produce sustainable polymers commercially and economically.
\end{abstract}

Keywords: Natural Phenols; Cardanol; Lignophenol; Sustainable Polymers; Phenolic Resin; Benzoxazine

\section{Introduction}

Next decade challenges and opportunities are vast and alarming with the current use of non-renewable based chemical sources for synthesis of polymers and other architectures. There is a need to explore agricultural waste materials for synthesis of polymers such as phenolic resins, polyesters, polyurethanes, etc. Phenolic sources are vast and widely distributed in wood, seeds, shell, cashew nut shell liquid (CNSL), lignin, palm oil and other plant-based resources which are usually thrown as agricultural and agro-based industrial waste, while lactic acid and long chain alcohols are derived from corn starch, soya bean and castor oil respectively. The extraction and utilization of renewable monomers for a variety of bio-based polymers have been investigated in the past.

However, there are several problems associated with naturally occurring renewable resources. These are (1) limited knowledge about the organic contents in the natural source, (2) varying percentage of chemical content and composition with species, geographical area, and climatic conditions (3) usually, a complex Department of Science \& Technology, Delhi, India chemical composition of the extracted material comprising of several compounds such as phenols, carboxylic acids, aldehydes, esters etc. needs higher costs of desired chemical recovery, (4) low percentage of the desired chemical species requires further processing and adds to additional costs.

The shifting of the resource base for organic chemicals from fossil fuels to renewable resources creates a unique opportunity for shifting plastics from their current unsustainable course to a more sustainable life cycle. The research in this area is still at a nascent stage and scientists have to unfold the chemistry in this upcoming area.

\section{Sources of Renewable Materials}

\subsection{Naturally Occuring Phenolic Compounds}

Currently the agricultural wastes such as empty fruit bunches [1], seed [2-3], fibre, shell [4], wood, bagasse [5] are being investigated as a potential source of phenolic derivatives. Their main utilization at the moment is to generate energy to run the mill by incinerating the waste for power and fertilizer purposes. However, these wastes are rich in potential chemicals and pyrolysis is considered to be an emerging and potential technology to produce value added products, fuel, oil and chemicals from such waste. Moreover, an appropriate separation and extraction method is required to maximize the desired chemical from the agricultural waste. Some of these materials contain a very high concentration of phenol and its derivatives, viz., cresol, catechol, guaiacols, syringol, eugenol etc. These products are very high-value chemicals from the point of view of price, lower toxicity and environmental impact as compared to petroleum based products. Such waste could be utilized as an alternative source of phenols and its derivatives for the variety of applications ranging from the production of polymers and resins. The main naturally occurring phenolic sources that will be considered are cashewnut shell liquid (CNSL, Figure 1), lignins (Figure 2), palm oil and coconut shell tar.

\subsection{Naturally Occuring Acids}

Lactic acid is major by product of carbohydrate hydrolysis. It is one of the most studied renewable monomer. The monomer 
(a)<smiles>[R]c1cccc(O)c1C(=O)O</smiles>

(b)<smiles>[R]c1cccc(O)c1</smiles><smiles>[R]c1cc(O)cc(O)c1</smiles>

(d)<smiles>[R]c1cc(O)c(C)c(O)c1</smiles>

$\mathbf{R}=$

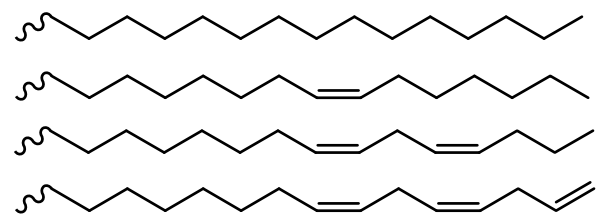

Figure 1. Components in CNSL: (a) anacardic acid, (b) cardanol, (c) cardol, (d) 2-methylcardol [4].

L-lactide (LLA) can be prepared with relatively high enantiopurity from corn starch fermentation.

\subsection{Naturally Occuring Alcohols}

1) Vegetable oils

Vegetable oils are triglycerides of long chain fatty acid moieties (Figure 3), with unsaturated bonds and free hydroxyl groups. The ester moieties are hydrolyzed to give carboxylic acid functionality (Figure 4).

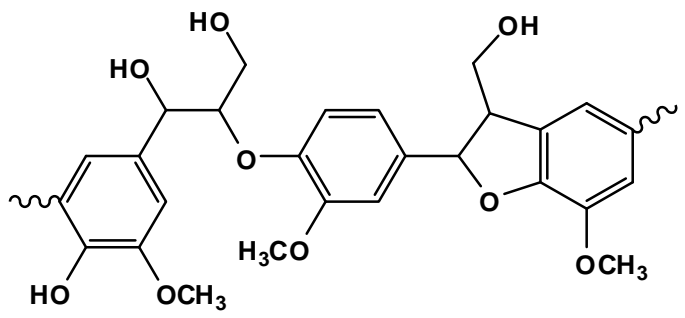

Figure 2. Representative structure of (a) Lignin [6].<smiles>[R]C(=O)OCC(COC([R])=O)OC([R])=O</smiles>

Figure 3. Triglycerides $\mathbf{R} 1=\mathrm{R} 2=\mathrm{R} 3$ (aliphatic unsaturated or saturated).

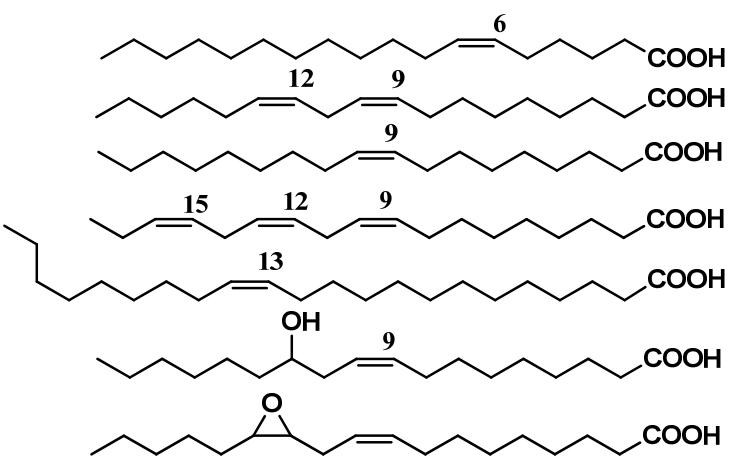

Figure 4. Modifications and occurrence of fatty acid in oils: source for monomers and polymers from renewable resources [7].
Soyabean oil triglycerides are a-linolenic acid (18C, 3 double bonds, 7-10\%); linoleic acid (18C, 2 double bonds, 51\%); and oleic acid (18C, 1double bond, 23\%). Mustard oil contains erucic acid (22C, 1double bond, 42\%), linolenic and linoleic acid (21\%), oleic acid (12\%). Castor oil consists of ricinoleic acid (85-95\%) which is monounsaturated, 18-carbon fatty acid, is unusual in that it has a hydroxyl functional group on the 12th carbon.

2) Glycerol

Glycerol (propan-1,2,3-triol) is a byproduct of soap industry as result of transesterification reaction of fat in alkaline medium to form soap (Figure 5).

Products such as glycerol carbonate and esters are good intermediates for several polymers (Figure 6) [8].

Mono-di-or tri ester could be produced by esterification with carboxylic acid or transesterification with carboxylic acid methylesters (Figure 7) [9].

\section{Polymers}

Incorporation of monomers obtained from green sources provides new significant synthetic aspects and helps to produce partly green goods with a finite content of renewable or recyclable material extracted without odor problems and less use of fossil fuel reserves.

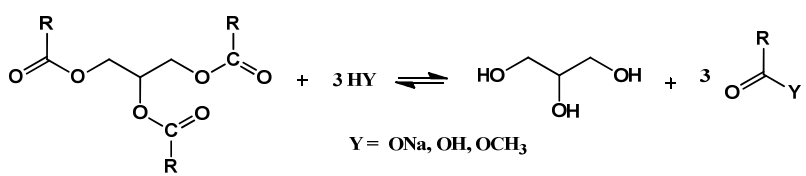

Figure 5. Transesterification of fatty acid.<smiles>CC(=O)C(C)(C)C(=O)O</smiles>

Figure 6. Utilization of greener sources namely glycerol and carbon dioxide to prepare carbonate.<smiles>[R]C(=O)OC[C@@H](O)COCC(O)CO</smiles>

Figure7. Monoesters of diglycerol. 


\subsection{Polymers Obatined from Phenolic Materials}

The presence of phenolic - $\mathrm{OH}$ group, aromatic ring and side chains such as long alkylene chain in cardanol, could be utilized for various chemical transformations. Lignins have phenolic hydroxyl groups and aliphatic groups at C-a and C-g positions on the side chain. The presence of such groups has enabled its utilization as a partial substitute for phenol in the synthesis with a lot of applications. The reactivity of lignin is determined both by its particular structure with specific functional groups and its structural modifications induced by separation methods derived from different raw materials.

1) Reactions due to - $\mathrm{OH}$ group
A variety of functional groups can be attached to the reactive free hydroxyl group for derivatization. The reactions may be divided into two categories a) nucleophilic aromatic/aliphatic substitution (b) condensation reaction. A generalized scheme for the possible modifications of $-\mathrm{OH}$ groups in naturally occurring phenolic compounds (Figure 8). Benzoxazines (Bzs) monomers are bicyclic heterocycles generated by the Mannichlike condensation of a phenol, formaldehyde and an amine [10] (Figure 9). Our group reported replacement of petro-based phenolic compounds with agro-waste cardanol to synthesize mono- and bis-oxazine derivatives using solventless method and studied its ring-opening polymerization (ROP) to polybenzoxazine [11-13].

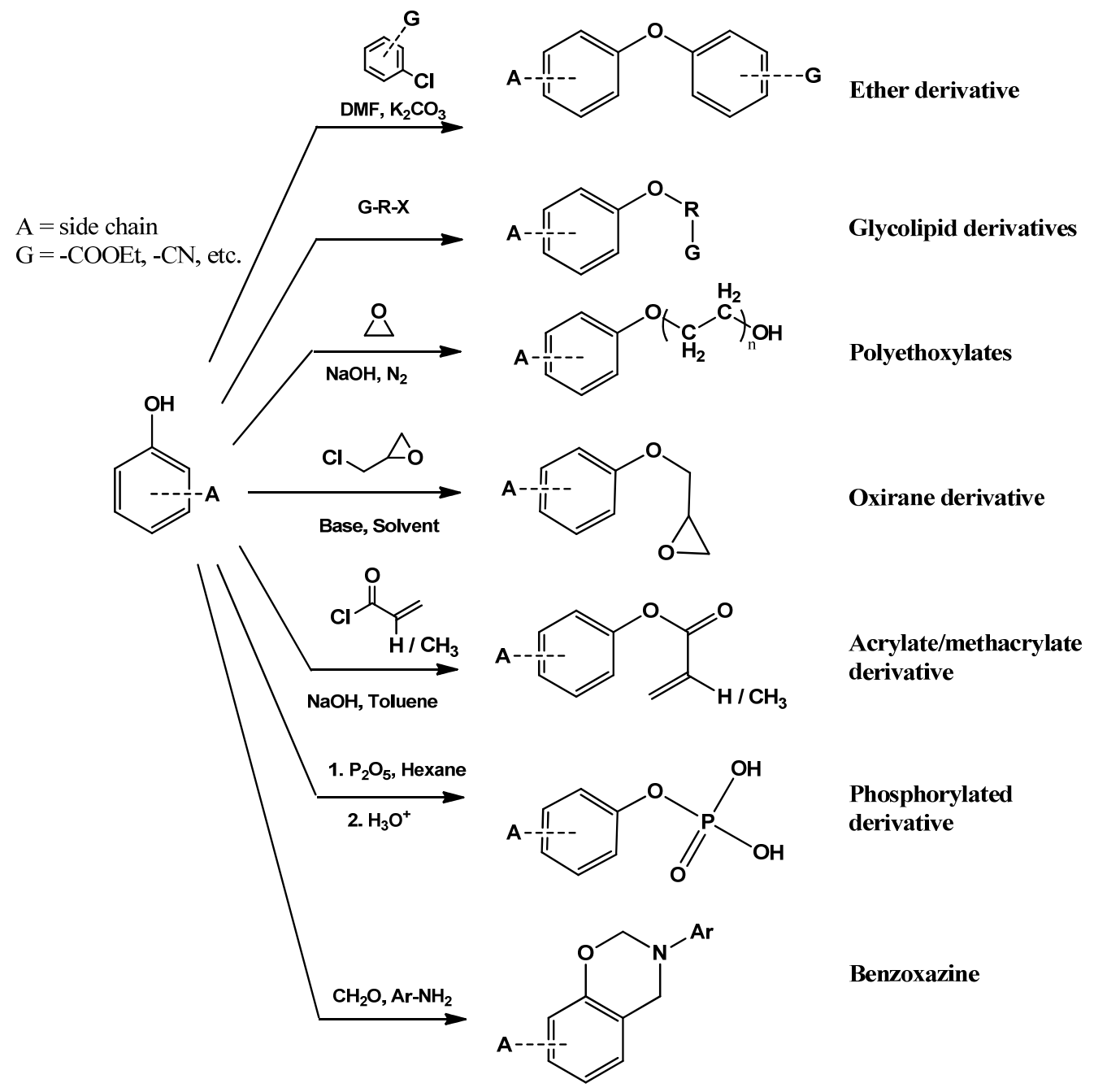

Figure 8. Modification of cardanol.<smiles>[R]c1cccc2c1CN([R])CO2</smiles>

Figure 9. Synthesis of 3,4-dihydro-2H-1,3-benzoxazines. 
2) Reactions due to aryl group

Aryl group present in lignophenol, cardanol, palm oil and CST undergoes electrophilic aromatic substitution reactions. A generalized reaction pathways possible for such structural modifications shown in Figure 10.

3) Reaction due to side chain

Depending on the source of phenolic compound (i.e. cardanol, palm oil, lignophenols) the side group may be alkylene chain, methyl or methoxy group etc. The modification of side chain allows further possibilities to tailor the structure. The polymers obtained from the phenolic monomers can be either used as such crude or modified.

Naturally occurring phenolic compounds could act as a source for synthesis of several polymers (Figure 11).

\subsection{Polymers from Lactic Acid}

High molecular mass poly(lactic acid) (PLA, Figure 12) is obtained either by the polycondensation of lactic acid or ROP of the cyclic dimer 2,6-dimethyl-1,4-dioxane-2,5-dione commonly referred as dilactide or lactide. PLLA is a versatile, semi-crystalline, degradable polymer having excellent mechanical properties, good biocompatibility and low toxicity. It has been used in a variety of applications in the pharmaceutical and biomedical fields, as well as used as a degradable plastic for disposable consumer products. In tissue engineering, PLLA has been used as biodegradable scaffold where the transplanted cells can remold their intrinsic tissue super-structural organization and thereby lead to the desirable 3-dimensional structure and physiological functionality of a regenerated organ. The properties of PLLA can be tailor made by copolymerization (random, block, and graft), change in molecular architecture (hyperbranched polymers, star shaped, or dendrimers), functionalization (end group functionalization or pendant groups such as carboxyl, amino, or thiol), or blending with other polymers [14].

\subsection{Polymers from Alcohol}

Aliphatic fatty acids saturated and or unsaturated acids are present in vegetable oils. They contain hydroxyl, carboxylic functionality and double bonds which are available for further functionalization to transform them to respective monomers [7] e.g. linseed oil, soyabean oil, sunflower oil, rape seed oil, castor oil, mustard oil, palm and coconut oil etc. These oils can be used in

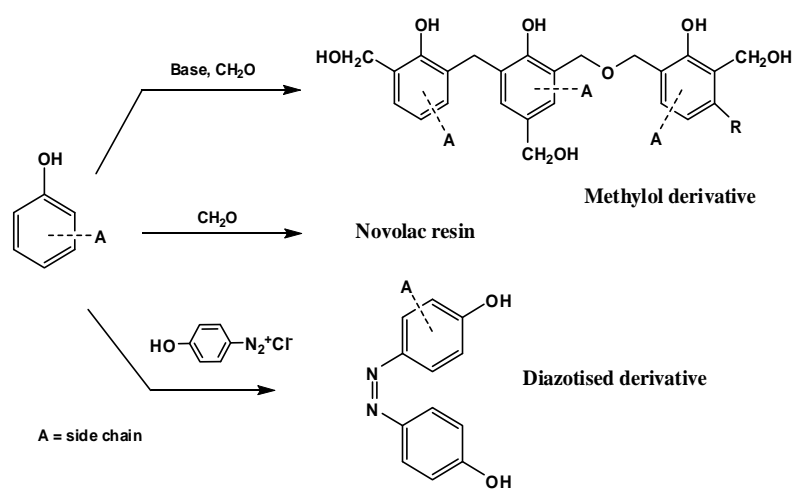

Figure 10. Modifications of aromatic ring synthesis of polyurethane, polyester, polyamide, polyacrylate, nylon and epoxy resin. For example, ozonolysis of oleic acid yields polyamide 6.9 ; ricinoleic acid which may be used to give polyamide 10.10 and 6.10; 11-undecanoic acid obtained from castor oil has been used for the production of nylon-11, polyamide 6.10 and polyols from sources such as castor oil are undertaken by several industries such as Emery Oleochemicals, Evonik, Arkema, BASF [15]. The industry needs to become more competitive and this includes breeding strains of plant with higher levels of useful fatty acids, like high oleic acid containing sunflower oil.

Glycerol dimethacrylate diester monomer can be used for the synthesis of copolymers [16], glycerol carbonate for synthesis of hyperbranched polymers [17].

\subsection{Utility of Carbon Dioxide}

Carbon dioxide is green, environmentally benign, solvent and reactant that is cheap, non-toxic, non-flammable and naturally abundant. It can be fixed and inserted in various compounds (Figure 13) to from cyclic carbonates, caboxylates, carbamates, urea, salicylates etc.

The cyclic carbonates prepared by insertion of carbon dioxide into an oxirane ring of ethylene/propylene oxide to form 5/6-membered cyclic carbonates which then undergo ringopening polymerization to form polycarbonates (Figure 14).

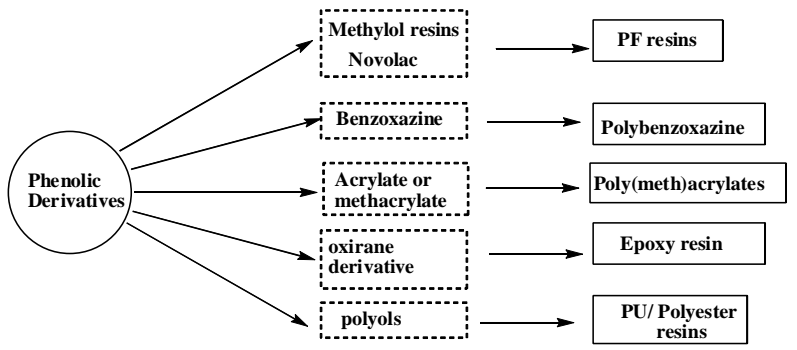

Figure 11. Scheme depicting polymers obtained from naturally occurring phenolic monomers.<smiles>CC(C)(C)OC(=O)C(C)(C)C</smiles>

Figure 12. Poly(lactic acid).
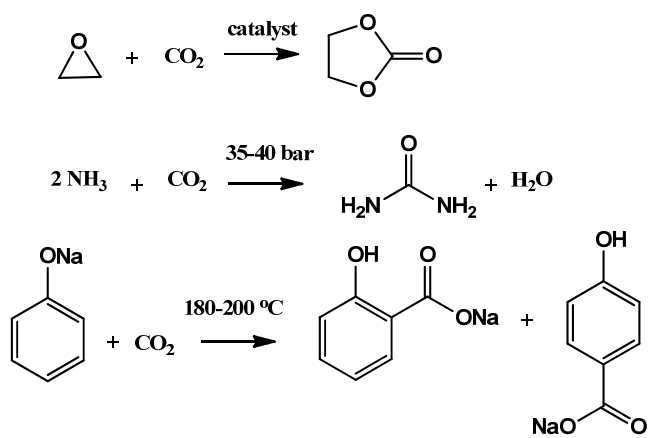

Figure 13. Carbon dioxide as the reactant for various monomer synthesis. 


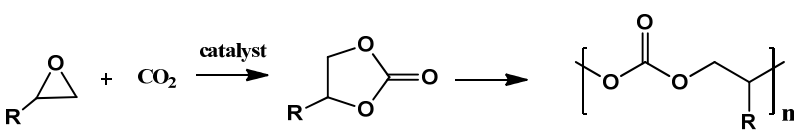

Figure 14. Ring-opening polymerization of cyclic carbonates.

Unlike aromatic polycarbonates which either use toxic phosgene or diphenyl carbonate which accounts for high toxicity, these showed good bio-compatibility, biodegradability, low toxicity, and find applications in biomedical fields [18].

\subsection{Conclusion}

The surge in living standards resulted in more dependence on polymers articles for our daily needs. The usage of non-renewable based materials affects our environment tremendously and measures are required to deal with it both scientifically and globally. Polymers derived from renewable starting materials are attractive because of safety and ecology issues over petrobased materials such as (a) environmental and economic concerns associated with waste disposal and (b) rising cost of petroleum production resulting from the depletion of the most easily accessible reserves. These are the guiding principles for the next generation polymers which have zero or less ecology impact, sustainability, eco-efficiency and green chemistry. Biopolymers based on renewable resources include cellulosicplastics, polylactides (PLA), starch-plastics, soy-plastics, phenol plastics.

The challenge for development of biodegradable polymers lies in the fact that such polymers should be able to be processed on the existing equipments, stable during storage and usage, and degrade when disposed off after their intended lifetime [19]. There is a need for a research to develop new techniques for utilization of renewable resources to synthesize new intermediates/monomers for polymers for greener sustainable future.

\section{REFERENCES}

[1] J. M. Kawser and A. F. Nash, "Oil palm shell as a source of phenol”, J. Oil Palm Res., 12, pp. 86-94, 2000.

[2] H. Kozlowska, D. A. Rotkiewicz, R. Zadernowski and F. W. Sosulski, "Phenolic acids in rapeseed and mustard", J. Am. Oil Chem. Soc., 60, pp.1119-23, 1983.

[3] L. Zahradníková, Š. Schmidt, Z. Sékelyová and S Sekretár, "Fractionation and identification of some phenolics extracted from evening primrose seed meal”, Czech. J. Food Sci., 26, pp. 58-64, 2008.

[4] D. Wasserman and C. R. Dawson, "Cashew nut shell liquid: comparison of the monophenol isolated from commercial raw cashew nut shell liquid and from commercial cardanol”, Ind. Eng. Chem., 37, pp.396-9, 1945.
[5] E. R. Leal, R. R. Vaquez and T.Galindo, "Separation of phenolic compounds from sugarcane bagasse pith and their determination by HPLC”, J. Wood Chem. Tech., 14, pp. 369-82, 1994.

[6] E. Dorrestijn, L. J. J. Laarhoven, I. W. C. E. Arends, and P. Mulder, "The occurrence and reactivity of phenoxyl linkages in lignin and low rank coal”, J. Anal. Appl. Pyrolysis,54, pp.153-92, 2000.

[7] M. A. R. Meier, "Metathesis with oleochemicals: new approaches for the utilization of plant oils as renewable resources in polymer Science”, Macromol. Chem. Phys., 210, pp. 1073-1079, 2009

[8] A. Behr, J. Eilting, K. Irawadi, J. Leschinski and F Lindner, "Improved utilisation of renewable resources: New important derivatives of glycerol”, Green Chem., 10, pp. 13-30, 2008.

[9] J. Barrault, J. M-. Clacens, Y. Pouilloux, "Selective oligomerization of glycerol over mesoporous catalysts: catalytic conversion of renewables”, Topics in Catalysis, 27, pp. 137-142, 2004.

[10] N. N. Ghosh, B. Kiskan and Y. Yagci, "Polybenzoxazines-new high performance thermosetting resins: Synthesis and properties”, Prog. Polym. Sci., 32, pp. 1344-1391, 2007.

[11] B. Lochab, I. K. Varma and J. Bijwe, "Thermal behaviour of cardanol-based benzoxazines: Monomers and polymers”, J. Therm. Anal. Calorim., 102, pp.769-774, 2010.

[12] B. Lochab, I. K. Varma and J. Bijwe, "Blends of benzoxazine monomers: Effect of structure and composition on polymer properties”, J. Therm. Anal. Calorim., DOI 10.1007/s10973-012-2469-1, pp.661-668, 2012.

[13] B. Lochab, I. K. Varma and J. Bijwe, "Cardanol based bisbenzoxazines: Effect of structure on thermal behaviour”, J. Therm. Anal. Calorim., 107, pp. 661-668, 2012.

[14] A. -C. Albertsson, I. K. Varma, B. Lochab, A. F. Wistrand and K. Kumar, "Design and synthesis of different types of poly(lactic acid)", In "Poly(lactic acid): Synthesis, Properties, Processing and Applications”, 2010, Eds. R. A. Auras, L. -T. Lim, S. E. M. Selke, and H. Tsuji, John Wiley \& Sons, Inc. 2010, Chapter 4, pp. 43-55.

[15] http://www.packagingeurope.com/Packaging-Europe-News/4737 0/Green-Chemistry-for-Polymers.html

[16] M. Roice, K. P. Subhashchandran, A. Gean, J. Franklin and V. N. R. Pillai, "Synthesis and characterization of glycerol dimethacrylate cross-linked polymethyl methacrylate: A resin for solid phase peptide synthesis”, Polymer, 44, pp. 911-922, 2003.

[17] G. Rokicki, P. Rakoczy, P. Parzuchowski and M. Sobiecki, "Hyperbranched aliphatic polyethers obtained from environmentally benign monomer: Glycerol carbonate, Green Chem., 7, pp. 529-539, 2005.

[18] U. Edlund, A. -C. Albertsson, S. K. Singh, I. Fogelberg and B. O. Lundgren, "Sterilization, storage stability and in vivo biocompatibility of poly(trimethylene carbonate)/poly(adipic anhydride) blends, Biomaterials, 21, pp. 945-955, 2000.

[19] A. -C. Albertsson, "Renewable green polymers", POLY344, 234th ACS National Meeting, Boston, MA, United States, August 19-23, 2007 